"Smallholder farmers' awareness of biofuel crops in the Eastern Cape Province, South Africa"

\begin{tabular}{|c|c|}
\hline AUTHORS & $\begin{array}{l}\text { Priviledge Cheteni (D https://orcid.org/0000-0002-1301-9486 } \\
\text { R http://www.researcherid.com/rid/L-5364-2013 }\end{array}$ \\
\hline ARTICLE INFO & $\begin{array}{l}\text { Priviledge Cheteni (2016). Smallholder farmers' awareness of biofuel crops in } \\
\text { the Eastern Cape Province, South Africa. Environmental Economics, } 7(3), 75-80 . \\
\text { doi:10.21511/ee.07(3).2016.09 }\end{array}$ \\
\hline DOI & http://dx.doi.org/10.21511/ee.07(3).2016.09 \\
\hline RELEASED ON & Friday, 21 October 2016 \\
\hline JOURNAL & "Environmental Economics" \\
\hline FOUNDER & LLC "Consulting Publishing Company "Business Perspectives" \\
\hline & $\begin{array}{l}\text { ニ-: } \\
\text { =-:- }\end{array}$ \\
\hline NUMBER OF REFERENCES & NUMBER OF FIGURES \\
\hline 0 & 0 \\
\hline
\end{tabular}

(C) The author(s) 2022. This publication is an open access article. 
Priviledge Cheteni (South Africa)

\title{
Smallholder farmers' awareness of biofuel crops in the Eastern Cape Province, South Africa
}

\begin{abstract}
In this study, 157 smallholder farmers from the OR Tambo and Chris Hani district municipality in South Africa were purposively sampled to participate in a survey. The objective was to identify the factors that influence smallholder farmers' awareness of biofuel crops. Using a binary logistic model, it was found that the variables: gender, household income, membership in association, land utilization and qualification were statistically significant in influencing farmers' awareness of biofuel crops. Therefore, it is recommended that the South African government should identify the smallholder farmers targeted for the biofuel program by their social status, as pointed in this study.
\end{abstract}

Keywords: awareness, binary model, biofuel industrial policy, energy, shared growth initiative, smallholder farmers. JEL Classification: Q1, Q2, Q4, Q5.

\section{Introduction}

Biofuels are described as solid, liquid, or gaseous fuel consisting of, or derived from biomass. Yet, biofuel crops are crops that are used to generate biofuels. These crops have been identified as a potential to the upliftment of smallholder farmers production and access to mainstream markets, especially in Africa (Takavarasha et al., 2005). Within the global village, many countries have embraced the idea of creating a biofuel industry. This has seen the booming of biofuel production worldwide, with ethanol production quintupled since 2000 and biodiesel production increasing 25 times (Wiggins et al., 2011). One of the reason is that energy demand has increased and it will continue to rise, especially in the developing world. In response to this challenge, a number of countries have drafted policies that are envisaged to create the biofuel industry. South Africa is one of the countries that launched a Biofuel Industrial Strategy Policy (BIS) to create a conducive environment for the biofuels market. The strategy was developed with a specific mandate of stimulating rural development leading to a contribution in the Accelerated and Shared Growth Initiative (AsgiSA), and reducing poverty through income-earning opportunities (BIS, 2007).

According to the Department of Mineral and Energy (DME), some of the factors that led to the creation of the strategy include the following: support for cleaner and environmentally friendly energy; support of renewable energy and the upliftment of the agricultural sector using surplus farming land; promoting sustainable development and improve energy security. To note are the BIS (2007) targets

(C) Priviledge Cheteni, 2016.

Priviledge Cheteni, Ph.D. in Agricultural Economics, Department of Agricultural Economics and Extension, University of Fort Hare, South Africa. of upliftment of agricultural sectors and unlocking of economic benefits in the Sub-Sahara region by attracting investments in rural areas and the promotion of agricultural development (BIS, 2007). This, in turn, is expected to help to overcome trade distortion that the Sub-Sahara region has faced with subsidized agricultural production. Since 2007, the Department of Minerals and Energy (DME) in collaboration with the Department of Agriculture, Fishery, and Forestry (DAFF) has been actively involved with smallholder farmers in the production of biofuels.

In South Africa, smallholder farmers face a number of challenges that impedes their growth and ability to contribute to agriculture. According to the Department of Agriculture Fishery and Forestry DAFF (2012), some of the challenges faced include lack of access to land, inadequate infrastructure, and institutional challenges. Smallholder farmers struggle to pay for inputs like fertilizers, seeds, to name a few. In order to address these challenges, the Biofuel Industrial Strategy Policy was launched. However, the awareness of biofuel crops has been very low.

Previous studies (McBride, 1999; McBride, 2003; Kinuthia, 2010; Dundedjrohoun et al., 2012) on awareness of technology or innovations in agriculture have failed to find a conclusive ground on what constitutes or influences awareness. McBride et al. (1999) study found that awareness was influenced by socio-economic characteristics; the most notable contribution was that it was in precision agriculture where farmers needed to be aware of new technology breakthrough in agriculture. Rogers (2003) reinforces this idea, but diverts by stating that when introducing new seed varieties or new technology, the first phase consists of making the farmers aware by demonstrations or other means. However, previous studies have dealt 
most on endogenous factors that usually affect farmers' awareness, for instance, Dundedjrohoun et al. (2012) measure the determinants of awareness of improved technology for rice parboiling and found that experience, membership of association, and ethnicity had an impact on farmer awareness.

In this current study, we extend on the available literature on awareness of agriculture innovations by including other farm characteristic variables like land utilized, and contact of extension officers as explanatory variables. We further add a dummy of municipalities to determine whether the origin of a farmer has an influence on awareness of biofuels crops. This is a valuable contribution to the current studies dealing with farmer awareness, especially in biofuels studies given that the Biofuel Industrial Strategy Policy was launched in 2007, and up to date, it is still under debate. We do not expect high level of awareness of biofuel crops by farmers in the study, especially in the Eastern Cape Province because of the lack of a clear path in including smallholder farmers in biofuel debates. Following a study done by Cheteni, Mushunje and Taruvinga (2014) on the potential adoption of smallholder farmers, it was identified that a number of farmers in the Eastern Cape Province were willing to adopt biofuel crops. Therefore, the current study draws a sample from a rain rich area and a dry irrigation fed area to identify the likely effects of geographical location on awareness of biofuel crops. This provides two set of samples of farmers, thus, their level of awareness is expected to be influenced by a number of factors based on geographic location.

The main objective of this paper is to determine factors influencing awareness of biofuel crops by smallholder farmers in the Eastern Cape Province, South Africa.

The paper is organized as follows: section 1 provides the data and methodology used in this study and section 2 presents the empirical results. Last section gives a conclusion and recommendations for the study.

\section{Methods and materials}

This section provides a description of the methods used in the study, and how the data were analyzed.

1.1. Study areas. The study used primary data collected in two municipalities, namely, Chris Hani District Municipality and the OR Tambo District Municipality. The OR Tambo District Municipality lies on the eastern coast of the Eastern Cape Province and has a population of over 1.74 million people (DAFF, 2012). The district has high levels of poverty, underdevelopment, and infrastructure backlogs (OR Tambo IDP, 2013). Furthermore, the municipality has a youthful population with over 39 percent of residents aged below 20 years and an unemployment rate of 40.8 percent (OR Tambo IDP, 2013). Poverty in the area is defined as deep and pervasive with at least 37.7 percent of residents living in squalid conditions (OR Tambo IDP, 2013). The Human Development Index is 0.40 as from 2009, although it increased from 3.8 in previous years, it still reflects a lack of access to basic services, high illiteracy rate, and low standards of living, similarly to the Chris Hani District Municipality. There are about 795461 people who live in Chris Hani District Municipality and they cover an area of $36558 \mathrm{~km}^{2}$ (Chris Hani IDP, 2013). At least 79 percent reside in the rural areas or former homelands, while the remainder is based in urban areas. Households headed by women contribute around 53.5 percent of the population and the predominant language is IsiXhosa spoken by 93.3 percent in the District (Chris Hani IDP, 2013).

1.2. Sampling technique. This study adopted a nonrandom purposive sampling technique to select the smallholder farmers. The selection of the first two farmers, one utilizing land, and the other not utilizing land was done using a snowballing sampling technique. The snowballing sampling technique is used to capture a range of perspectives relating to the thing under study. This technique helps in gaining deeper insights into units under study. The main reason for choosing this method was to focus on particular characteristics of the population of interest. This, in turn, helped in answering the objectives of the study.

In Chris Hani District, areas sampled had farmers partaking in irrigation farming and consisted of smallholder farmers utilizing and non-utilizing land. The two types of farmer groups were purposively selected in order to identify certain characteristics or traits that would help in identifying farmers that were likely to be aware of biofuel crops and those who would not. In the OR Tambo District, smallholder farmers selected were utilizing and nonutilizing land, but mainly those who were involved in rain-fed crop production. The selection of the sampled areas in each municipality was done purposively. A total of 79 farmers both land and non-land utilizers were selected from Chris Hani District Municipality and 78 farmers with similar characteristics were from the OR Tambo District Municipality.

1.3. Econometric model. The study made use of a binary logistic model. The probability of a dichotomous outcome is related to a set of 
explanatory variables in this statistical technique. Katwijuke (2004) noted that it is a statistical tool used to determine the influence of independent variables on dependent variables. The model can be used to predict a dependent variable based on continuous and categorical independent variables. In this study, the binary model is employed for these reasons.

$\operatorname{Prob}($ Event $)=\operatorname{Prob}(Y$, represents $i$ th farmer awareness to biofuel crops, and 0 otherwise)

Lex $X_{i}$ represents the set of parameters, which influence awareness of the $i$ th farmer. $Z_{\mathrm{i}}$ is a direct utility, which is a linear function of $k$ explanatory variables $(X)$ which is expressed as follows:

$Z_{i}=\beta_{0}+\sum_{i=1}^{n} \beta_{i} X_{k i}$,

where $\beta_{0}$ is the intercept, $\beta_{1}, \beta_{2}, \ldots \ldots \beta_{i}$ are coefficients associated with the explanatory variables $X_{i,} X_{2, \ldots . .} X_{k i .}$. Factors in a vector $X$ explain awareness or the probability of the $i$ th farmer being aware of biofuel crops:

$P_{i}=\frac{e^{z i}}{1+e^{z i}}$

where, $P_{i}$ denotes the probability that the $i$ th farmer is aware of biofuel crops and $\left(1-P_{i}\right)$ is the probability that the farmer is not aware of biofuel crops. The odds ( $\mathrm{Y}=1$ versus $\mathrm{Y}=0)$ to be used are defined as the ratio of the probability that the farmers are aware $\left(P_{i}\right)$ to the probability of non - awareness $\left(1-P_{i}\right)$, namely odds $=P_{i} /\left(1-P_{i}\right)$. By eliminating the natural $\log$, we get the following equation (Shaban et al., 2006):

$L_{i}=\operatorname{In}\left(\frac{P_{i}}{1-P_{i}}\right)$,

where $L_{i}=\log$ of odds ratio, $P_{i}=$ probability of being aware of biofuel crops and $\left(1-P_{i}\right)=$ the probability of being not aware to biofuel crops. The value of:

$P_{i}=\frac{1}{1+e^{-z t}}$

and the value of $Z_{i}$ is referred to as the $\log$ of the odds ratio in support of being aware of biofuel crops and is calculated as follows:

$Z_{i}=\beta_{0}+\beta_{1} X_{1}+\beta_{2} X_{2}+\beta_{3} X_{3}+\ldots \ldots . \beta_{n}+\mu_{i \ldots .}$,

where: $\beta_{0}=$ intercept term;

$\beta_{1}, \beta_{2}, \beta_{3} \ldots \beta_{n}=$ slope of the parameters of the model which measures $L i$ for a unit change in explanatory variables;

$X_{1} \ldots X_{n}=$ factors that explain awareness of biofuel crops or the probability that a farmer is aware of biofuel crops.

The variables used in this study and the expected signs are shown below in Table 1 .

Table 1. Variables used in the study

\begin{tabular}{|c|c|c|c|c|}
\hline Variable & Definition & Type & Unit of measurement & Sign \\
\hline \multicolumn{5}{|c|}{ Dependent variables } \\
\hline AWAREBIO & Awareness to biofuels & Binary & $1=$ aware $\& 0$ otherwise & \\
\hline \multicolumn{5}{|c|}{ Independent variables } \\
\hline GENDER & Household gender & Binary & $0=$ Female $\& 1=$ Male & $+/-$ \\
\hline AGE & Household age & Continuous & Years & $+/-$ \\
\hline QUALIFICA & Household education & Continuous & Level & $+/-$ \\
\hline UTILAND & Utilization of land & Binary & $1=$ yes $\& 0=$ no & $+/-$ \\
\hline FARMEXPE & Level of farming experience & Continuous & years & + \\
\hline HHINCOME & $\begin{array}{l}\text { Household income from } \\
\text { Agriculture }\end{array}$ & Binary & $1=$ yes $\& 0=$ no & + \\
\hline MEMBERASS & Member of association & Binary & $1=$ yes $\& 0=$ no & + \\
\hline AGRICEXT & $\begin{array}{l}\text { Contact with agriculture } \\
\text { extension agents }\end{array}$ & Binary & $1=$ yes $\& 0=$ no & + \\
\hline DISTRICT & Municipalities & Binary & $0=0 R$ Tambo \& 1 = Chris Hani & $-/+$ \\
\hline
\end{tabular}

Source: Budge (2008)

\section{Discussions and results}

The sampled farmers comprised of males who made 53 percent of the sample, and the remainder as females. This is the general norm in Africa, where most households are male headed or dominated. This observation is similar to Montshwe (2006) who discovered that males still dominate in the agricultural sector in South Africa. Cheteni (2014) found similar results in terms of gender in agriculture at the Eastern 
Cape Province. This may be attributed to the physical nature of agricultural activities which are mainly labor intensive. At least 52 percent of respondents interviewed were 35 years and over, but less than 50 years. The majority of respondents had at least a primary education. A total of 54 percent respondents stated that there are members of agricultural associations or societies. Being a member of an association serves as a network where valuable information pertaining to agriculture can be exchanged. The empirical results of the binary model are shown in Table 2.

Table 2. Binary model results

\begin{tabular}{|c|c|c|c|c|}
\hline Variable & Coefficient & Std. Error & z-statistic & Prob. \\
\hline C & 3.612244 & 1.223497 & 2.952394 & $0.0032^{* \star \star}$ \\
\hline AGE & -0.129830 & 0.295136 & -0.439900 & 0.6600 \\
\hline GENDER & 1.031320 & 0.425656 & 2.422897 & $0.0154^{\star \star \star}$ \\
\hline HINCOME & -0.579226 & 0.161986 & -3.575783 & $0.0003^{* \star \star}$ \\
\hline DISTRICT & -0.621936 & 0.402306 & -1.545928 & 0.1221 \\
\hline FARMEXPERI & 0.021235 & 0.302235 & 0.070258 & 0.9440 \\
\hline AGRICEXT & 0.249133 & 0.419154 & 0.594371 & 0.5523 \\
\hline MEMBERASS & 0.801515 & 0.459085 & 1.745897 & $0.0808^{*}$ \\
\hline UTILISELAND & 0.985993 & 0.479069 & 2.058142 & $0.0396^{* \star}$ \\
\hline QUALIFICA & -1.172762 & 0.270975 & -4.327942 & $0.0000^{\star \star \star}$ \\
\hline DISTRICT & 0.789891 & 0.410045 & 1.645636 & $0.0007^{* \star *}$ \\
\hline McFadden R-squared & 0.638158 & \multicolumn{2}{|l|}{ Mean dependent var } & 0.480620 \\
\hline S.D. dependent var & 0.501572 & \multicolumn{2}{|l|}{ S.E. of regression } & 0.273385 \\
\hline \multicolumn{2}{|l|}{ Number of observations } & \multicolumn{3}{|c|}{157} \\
\hline \multicolumn{2}{|l|}{-2 Log likelihood } & \multicolumn{3}{|c|}{109.235} \\
\hline \multicolumn{2}{|l|}{ Cox \& Snell $R$ Square } & \multicolumn{3}{|c|}{0.219} \\
\hline \multicolumn{2}{|l|}{ Nagelkerke $R$ Square } & \multicolumn{3}{|c|}{0.593} \\
\hline \multicolumn{2}{|c|}{ Hosmer and Lemeshow Chi-Square Test } & \multicolumn{3}{|c|}{$5.312(d f=8 ; p$-value $=0.724)$} \\
\hline \multicolumn{2}{|c|}{ Omnibus Tests of Model Coefficients Chi-square } & \multicolumn{3}{|c|}{524.630 (df $=9 ; p$-value $=0.003)$} \\
\hline \multicolumn{2}{|l|}{ Over all model prediction (\%) } & \multicolumn{3}{|c|}{$72 \%$} \\
\hline
\end{tabular}

Table 2 shows the results from the binary model that was estimated. Firstly, model fit tests were conducted to assess the robustness of the model. The likelihood ratio, omnibus tests of the model chi-square statistic and the Hosemer and Lemeshow test statistic were used to test the goodness-of-fit or predictive efficiency of the model (Table 2). The model explained about 59\% (Nagelkerke R2) of the variance in smallholder farmers awareness factors in biofuel crops and correctly classified about $72 \%$ of cases. The number of observation was 157 and the restricted Log likelihood value of 109.235 and the Cox $\&$ Snell were at $22 \%$. The Hosemer and Lemeshow Test is the most robust test or the model fit. Unlike the $p$-values, we want $\mathrm{p}=>0.05$ to indicate a good fit to the data. As shown in Table 2, the p-value is over 0.05 suggesting that there is no difference between the observed and the predicted model values of the dependent variable. The $-2 \log$ likelihood is a measure of how well the model explains variations in the outcome of interest. The $p$-value for the model is less than $p=0.05$, hence, we conclude that the addition of variables is statistically significant.

The results show that among the ten independent variables included in the model, only six were relevant in explaining the dependent variable. Gender was statistical by significant with a $p$-value of 0.015 and a positive coefficient close to one meaning that males were more aware of biofuel crops that females. Asfaw and Admassie (2004) found that male-headed households tend to receive information quickly about new technologies in agriculture as compared to female-headed households. Similarly, the Department of Agriculture Forestry and Fisheries (2012) pointed that female headed households had a low participation rate in agricultural activities. This, in turn, tends to affect their level of awareness on agricultural activities or innovations.

Household income was significant with a $p$-value of 0.003 , with a negative sign on the coefficient meaning that households with less income were found to be more aware of biofuel crops than those with more income. This was partly caused by the challenges faced by households with no income who are forced to look for opportunities of gaining extra income through farming. Hence, leading them to be aware of certain biofuel crops that have been proposed by the government, since they stand to benefit financial by participating in the biofuels market. 
Membership in agricultural associations was statistically significant with a p-value of 0.08 and with a positive coefficient. As expected, participation or belonging to a membership society in agriculture had an influence in the awareness of people on biofuel crops. This means that the more the individual attends or participates in agricultural associations the higher the chances of the individual receiving information that would make him/her aware of biofuel crops through discussions with other farmers. A study conducted by Dandedjrohoun et al. (2012) recorded a positive association between membership in association and awareness in new technology. The findings state that being involved in associations helps in the sharing of information through informal and formal discussion, which increase the awareness level.

The variable UTILISELAND measur arable land size was utilized during the last farming season. The variable was found to be statistically significant (coefficient: 0.985) in influencing awareness of farmers on biofuel crops. Ogada, Mwabu and Muchai (2014) pointed that the size of land cultivated by the household was positively correlated with awareness and adoption of new technology. Therefore, as expected, farmers who were utilizing land were found to be more aware than those who did not utilise land in the past seasons. The main reason was that non-land utilizers concentrated on livestock production, yet, land utilizers were heavily involved in farming.

Qualification or high level of education had a negative association with awareness of biofuels (coefficient: -1.172). This study had more respondents with at least primary level education who were more aware of biofuel crops. The finding of this study contradicts Daberkow \& McBride (2003), who discovered that higher education level increased the likelihood of awareness in agriculture technologies. Literature has been inconclusive on the effect of education on awareness of new technology or seed varieties.

Lastly, in terms of Municipalities where the respondents came from, it was found that respondents from Chris Hani District Municipality were more aware of biofuel crops, compared to the ones from the OR Tambo District municipality. This was not surprising considering that the Chris Hani district is a dry area, which is well suited for biofuel crops. Secondly, the area has large vast of unutilized land, compared to the OR Tambo, which means that a number of farmers are looking forward to utilize the land by farming biofuel crops.

\section{Conclusions and recommendations}

The paper examined the factors that influence or affect smallholder farmers' awareness of biofuel crops. Factors that were identified to be influencing farmers to be aware of biofuel crops were gender, household income, membership in association, land utilization, and qualification. Evidence from literature pointed that smallholder farmers usually struggle to increase their productivity partly because of the lack of awareness to certain agricultural innovations that can improve their production.

The findings of the study suggest that they are a number of ways in which smallholder farmers can be made aware of biofuel crops. Any adjustment in any of the significant variables has the potential to influence awareness of farmers. It should be noted that smallholder farmers also struggle in getting marketing information, which affects their level of awareness to certain agricultural innovations. Therefore, the Department of Agriculture Forestry an Fisheries through its extension officer program has a huge role to play in distributing relevant information to the respective farmers. This could be done by engaging with community leaders who are very useful in disseminating information, especially in rural areas. It is worth noting that smallholder farmers who are participating in farmer groups or associations have a high likelihood of getting up to date information on agriculture. Therefore, the suggestion is that farmers who are usually facing similar challenges should be grouped together so that these obstacles can be removed. It should be noted that some of the factors, which were affecting awareness like land utilization, could be solved easily through support schemes from the government. Farmers who were not utilizing land tend to neglect information on agriculture, because they would not be using it because of challenges they face. Hence, another way of improving farmers' awareness is through input support schemes.

Future studies can focus on understanding the role played by awareness in the adoption of biofuel crops national. This includes testing other factors such as policy impacts on smallholder farmers. The main shortcoming of the study was that it focused on one region in South Africa. This means that the findings can only be generalizable to the study area or any area resembling similar characteristics to the study area. 


\section{References}

1. Asfaw, A. and Admassie, A. (2004). The role of education on the adoption of chemical fertilizer under different socioeconomic environments in Ethiopia, Agricultural Economics, 20(3), pp. 215-228.

2. Biofuels Industrial Strategy (BIS) of the Republic of South Africa. (2007). Department of Minerals and Energy. Available at: http:// www.info.gov.za/view/DownloadFileAction?id=77830. Accessed on February 2015.

3. Chris Hani IDP. (2013). Chris Hani District Municipality IDP 2013-14 Review. Government Printers.

4. Daberkow, S. and McBride, W. (2003). Farm and operators characteristics affecting the awareness and adoption of precision agricultural technologies in USA, Precision Agriculture, 4(2), pp. 163-177.

5. Dandedjrohoun, L., Diagne, A., Biaou, G., N'cho, S. and Midingoyi, S. (2012). Determinants of diffusion and adoption of improved technology for rice parboiling in Benin, Review of Agricultural and Enviromental Studies, 93(2), pp. 171-191.

6. Department of Agriculture Forestry and Fisheries. (2012). Agricultural statistics. Available at: http://www.nda.agric.za/docs/statsinfo/Ab2012.pdf. Accessed on 14 October 2015.

7. OR Tambo IDP. (2013). OR Tambo Integrated Development Plan Review 2013-14. Government Printers.

8. Katwijukye, A.K. (2005). Socio-Economic Analysis of Land Resource Use and Conservation in Uganda. W. Doppler, S. Bauer, (eds.), Farming and Rural Systems Economics, 71.MargrafVerlag, Weikersheim.

9. Montshwe, D. (2006). Factors affecting participation in mainstream cattle markets by smallholder cattle farmers in South Africa. Bloemfontein: University of Free State.

10. Ogada, J.M., Mwabu, G. and Muchai, D. (2014). Farm technology adoption in Kenya: a simultaneous estimation of inorganic fertilizer and improved maize variety adoption decisions, Agricultural and Food Economics, 2 (12).

11. Wiggins, S., Keane, J., Kennan, J., Leturque, H. and Stevens, C. (2011), Production, policy and trade opportunities for biofuels in Eastern Africa. Research Report, Bioenergy in Africa: opportunities and risks of jatropha and related crops Consortium. London: Overseas Development Institute.

12. Takavarasha, T., Uppal, J. and Hongo, H. (2005). Feasibility Study for the production and use of biofuel in the SADC region. Gaborone: SADC. 